\title{
TRADIÇÃO LETRADA E CINEMA MUDO: \\ EM TORNO DE ALGUMAS CRÔNICAS \\ MEXICANAS DE COMEÇOS DO SÉCULO XX
}

Miriam V. Gárate

Durante o período em que o cinema foi um espetáculo mudo, embora não necessariamente silencioso - grosso modo, até 1930 -, a reflexão sobre suas relações com a escrita e, em um sentido mais amplo, com a linguagem verbal, organizou-se basicamente em torno de três eixos. Primeiramente, na medida em que o desenvolvimento da linguagem fílmica orientou-se de imediato predominantemente em direção ao narrativo, o qual implicou um intenso aproveitamento de fontes literárias, instaura-se uma discussão sobre o caráter bem-sucedido ou não dessas transposições, e sobre os gêneros escritos que possuem, em hipótese, uma afinidade maior com a estética da lente. Em seguida, e enquanto desdobramento "técnico" da problemática anterior, na medida em que a expansão da narrativa cinematográfica viu-se associada não poucas vezes à proliferação dos letreiros, avalia-se a função desse tipo de escrita no contexto fílmico. Por último, e comportando uma questão de caráter mais amplo, que de certa forma engloba ou inclui as anteriores, instaura-se uma reflexão sobre as possibilidades e impossibilidades "inerentes" às linguagens visual e verbal, sobre suas respectivas propriedades específicas, limitações e potencialidades. Evidentemente, aquilo que permeia esse conjunto de debates é a necessidade premente de negociar hierarquias e papéis no seio da cultura. Os setores letrados, primeiros responsáveis pelo desenvolvimento de uma incipiente crítica cinematográfica, dada sua condição de cronistas da vida urbana e do espetáculo teatral, perguntam-se, implícita ou explicitamente, pelo estatuto do escrito - e em especial, do escrito literário -, nesse horizonte drasticamente transformado pelo imediato sucesso de Méliès e as fitas italianas primeiro, de Griffith depois, de Chaplin, Murnau ou Cecile De Mille pouco mais tarde.

No âmbito latino-americano, a abordagem dessa série de questôes é comum a numerosos intelectuais pré-modernistas e modernistas (cabe lembrar mais uma vez o "desacordo" de denominações existentes a esse respeito entre Hispano-América e Brasil: o mo- 
dernismo hispano-americano corresponde àquilo que a historiografia literária brasileira reúne sob o nome de pré-modernismo; o modernismo brasileiro corresponde ao que na Hispano-América recebe a denominação genérica de vanguarda). Todavia, se o fato de focar os mesmos assuntos irmana os mexicanos José Juan Tablada (1871-1945), Luis G. Urbina (1864-1936), Carlos Noriega Hope (1896-1944), Jaime Torres Bodet (1902-1974), ao uruguaio Horacio Quiroga (1878-1837), aos argentinos Leopoldo Hurtado (1894-1980) ou Manuel Ugarte (1875-1951), aos brasileiros João do Rio (1881-1921), Monteiro Lobato (1882-1948) ou Mário de Andrade (1893-1945), a perspectiva adotada, com freqüência, os distingue. Não raro, um idêntico julgamento adotado como ponto de partida acarreta conclusōes divergentes, contrastantes, inclusive antagônicas. Assim, por exemplo, a comum pressuposição da escrita enquanto código mais complexo e abstrato que o código visual e deste, em conseqüência, enquanto código mais "simples" e direto, de compreensão mais imediata, torna-se exaltação da força educativa e do poder de propagação da cultura por meio do cinema em Monteiro Lobato ou Horacio Quiroga, ao passo que é motivo de rebaixamento no quadro geral das manifestaçôes artísticas para José Juan Tablada ou Luis G. Urbina.

O presente ensaio objetiva analisar algumas das posturas assumidas pelos setores letrados em torno dos três eixos de discussão aos quais me referi, adotando como corpus principal um conjunto de crônicas mexicanas, redigidas entre meados dos anos dez e meados da década vinte. $\mathrm{O}$ privilégio concedido a esse corpus fundamenta-se não apenas no valor das crônicas per se, como no fato de que é no México onde mais se tem avançado no levantamento e compilação desse tipo de material, ${ }^{1}$ tarefa a ser realizada no Brasil, na Argentina

\footnotetext{
${ }^{1}$ Entre as principais antologias e compilações, relativas a períodos ou autores de interesse para o presente trabalho, cabe mencionar: ALMOINA, Helena (org). Notas para una historia del cine mexicano (1896-1924). México: Filmoteca Unam, 1960-1980, 2 v.; GONZÁLES CASANOVA, Manuel (org). El cine que vió Fósforo. Alfonso Reyes y Martín Luis Guzmán. México: FCE, 2003; Los escritores mexicanos y los inicios del cine. 1896-1907. México DF/ Culiacán: Unam/El Colegio de Sinaola, 1995; MIQUEL, Ángel (org). Los exaltados. Antología de escritos sobre cine en periódicos y revistas de la ciudad de México 1896-1929. Guadalajara: Universidad de Guadalajara, 1992; El nacimiento de una pasión: Luis G. Urbina, primer cronista mexicano de cine. México: UPN, 1996; Por las pantallas. Periodistas del cine mudo. Guadalajara: Universidad de Guadalajara, 1996; TORRES BODET, Jaime. La cinta de plata (Crónica cinematográfica). México: Unam, 1986; NORIEGA HOPE, Carlos. El mundo de las sombras: el cine por dentro y por fuera (1921). México: Librería Editorial Andrés Botas e Hijo, 1921.
} 
e certamente em outros países hispano-americanos. ${ }^{2}$ Antes, entretanto, de centrar a análise nas relações palavra/imagem implicadas nesses três eixos, considero oportuno efetuar um pequeno desvio e revisar o que se vê, isto é, o que os letrados vêem nas primeiras projeçôes públicas do cinematógrafo. Em outros termos: aquilo que se vê em um momento em que a narratividade fílmica não está consolidada como caminho hegemônico, prevalecendo o fascínio inicial suscitado pelas vistas dos irmãos Lumière e de seus emissários (que rapidamente vieram projetar e capturar imagens nas principais cidades da América Latina) ou dos proto-cineastas locais. ${ }^{3}$

Nos periódicos, uma das primeiras notas, de autoria do reconhecido poeta e escritor Luis G. Urbina, permite apreender a potência celebrada e o limite constatado - ainda que superficialmente nesta nota -, em relação ao aparelho que se apresenta como uma das grandes atraçôes da capital mexicana desde finais de 1895. Refiro-me a "El cinematógrafo", crônica publicada em El Universal de 23 de agosto de 1896.

Valendo-se do recurso de personificação, pois Urbina organiza seu texto à maneira de um passeio da "Fantasia", esboça-se uma breve arqueologia dos dispositivos óticos prévios ao aparelho cinematográfico e que nele culminaram. Desfilam, dessa forma, diante dos olhos do leitor, os "óculos de Hans Schnaps", a "exposição imperial", o "kinetoscópio" de Edison e, finalmente, o cinematógrafo. Nesse percurso, a fixidez das imagens fotográficas dá lugar ao movimento, as figuras de reduzidas dimensões ganham um tamanho semelhante ao "normal" e "saem" da "moldura" e a desconfortável

\footnotetext{
${ }^{2}$ Um trabalho pioneiro nesse sentido, apesar do reduzido número de crônicas reunidas e da extensa cronologia que abrange, é o de Jason Borge. Avances de Hollywood. Critica cinematográfica em Latinoamérica, 1915-1945. Rosario: Beatriz Viterbo, 2005.

${ }^{3}$ Para uma abordagem historiográfica dos primeiros tempos do cinema no México cf. entre outros: REYES, Aurelio de los. Filmografía del cine mudo mexicano (1896-1920). México: Filmoteca Unam, 1986 e "Vivir de sueños", el cine mudo en México de 1896 a 1920. vol. I. México: Filmoteca Unam, 1983; LEAL, J F; BARRAZA, E; FLORES C. El Vitascopio y el cinematógrafo en México; 1897. Los primeros exhibidores y camarógrafos nacionales; 1900: El cine y los teatros; 1902 (Anales del cine de México 1895-1911, 2 v.. México: Ediciones EónVoyeur, 2002; MIQUEL, Ángel. Disolvencias. Cine, literatura y radio en México, 1900-1950, Fondo de Cultura Económica: México, 2005.
}

* (MIQUEL, Ángel (org). EI nacimiento de una pasión: Luis G. Urbina, primer cronista mexicano de cine. México: Universidad Pedagógica Nacional, 1996: 53-58.) 
(El mundo, 20/3/1899.)

" "Charla de los domingos", El Monitor Republicano, 6/9/1896.)

" ("Dominicales", El Universal, 12/12/1896.)

- ("México sugestionado. El espectáculo de moda", EI Imparcial, 16/10/1896.) postura do espectador - obrigado a permanecer de pé, inclinar-se sobre a caixinha de madeira e flagrar a cena através de um orifício - torna-se finalmente confortável. Projetadas em um ambiente de penumbra, sobre uma tela ou um muro, essas imagens são a duplicação quase perfeita da realidade exterior; apresentam "um fragmento de vida, clara e sincera, sem pose, sem fingimentos, sem artifícios". "Diante desse efeito de real, as carências, de som e de cor, são inicialmente pouco relevantes e passíveis de serem remediadas com o tempo (nesse sentido, o postulado caro a André Bazin e a Edgar Morin de que a utopia do "cinema total" - entendido como reprodução perfeita e integral da realidade - está presente desde as origens do cinema é correto e pode ser corroborado por numerosos escritos da época).

O reconhecimento da superioridade do cinematógrafo no que tange à duplicação do real material externo se comparado a outros dispositivos óticos, mas também à força mimética da representação verbal, pode ser lido em várias crônicas desses anos, redigidas por grandes nomes das letras mexicanas: Amado Nervo, Enrique Chávarri, " José Juan Tablada. ${ }^{*}$ É deste último, aliás, uma magnífica definição que exigiria por si só um estudo detalhado: "o cinematógrafo é o Zola do impossível". *

Captar (capturar), registrar, projetar, perpetuar: operações imbricadas que fazem do cinematógrafo uma autêntica "maravilha técnica”, conforme expressão utilizada por Urbina, que manifesta de maneira eloqüente a clivagem romântico-positivista ou fantástico-cientificista dessa percepção inicial. ${ }^{4}$ Nessa instância de "cópia"

\footnotetext{
${ }^{4}$ Ilusão de vida (movimento) e "supressão da morte" - isto é, cancelamento da irreversibilidade inerente à movência temporal graças à possibilidade instaurada pela projeção repetida - constituem duas faces de uma mesma moeda nessas primeiras crônicas, nas quais deparamos com afirmaçōes da seguinte ordem: "El día, figúrense ustedes, en que se pueda unir el cinematógrafo con el fonógrafo los muertos resucitan, pueden ser evocados como en las sesiones espíritas, pueden ser llamados de la eternidad para ser obligados a hablar, a moverse, a volver a la vida, ellos que tan cómodos deben hallarse en el país de los espectros. Cada hijo de vecino o de vecina, puede tener a sus muertos queridos grabados en una película fotográfica sistema Lumière, y de allí lanzarlos por medio de la linterna mágica a la blanca pantalla para verlos animarse, al tiempo que el fonógrafo habla con la voz misma de aquellos que fueron [...] El mundo marcha, no cabe duda, ya vamos camino de la inmortalidad. (Enrique Chavarri, "Charla de los domingo", El Monitor Republicano, 6/9/1896. In: GONZÁLEZ CASANOVA, M. (org). Los escritores mexicanos y los inicios del cine. 1896-1907. México D.F / Culiacán: Unam/El Colegio de Sinaola, 1995: 84-5) "O dia, imaginem só, em que for possível unir o cinematógrafo ao fonógrafo, os mortos ressuscitarão, po-
} 
do mundo material, de "reprodução" de objetos e de atos visíveis, o cinematógrafo revela-se um instrumento ímpar, revelando, por sua vez, o limite da escrita e, de modo geral, da linguagem quanto ao exercício dessa função. O cinematógrafo é ainda, supostamente, uma máquina de "mostrar" e aquilo que se mostra "vê-se melhor e mais nitidamente" que na letra.

Ocorre que de imediato o cinematógrafo torna-se cinema e, predominantemente, cinema narrativo. ${ }^{5} \mathrm{Na}$ rápida passagem da condição de "curiosidade", de "maravilha técnica", à de espetáculo baseado na projeção de fitas que re-apresentam acontecimentos verídicos ou representam histórias fictícias (quando não mesclam ambos os registros, como nas reconstituições históricas), dá-se um contato decisivo entre literatura e cinema. Essa primeira apreensão do fílmico "nas malhas da letra" possui, como já foi assinalado, duas facetas inter-relacionadas: por um lado, durante as primeiras décadas, o cinema sacia uma e outra vez sua sede de histórias no manancial literário, isso tanto por razões práticas - há nele um repertório pronto, testado, conhecido por uma parte do público - quanto devido ao desejo de reconhecimento do cinema no quadro geral das artes. Por outro lado, são precisamente os escritores, embora não só eles, os responsáveis pelos primeiros tateios reflexivos sobre as características da nova arte cujo estatuto artístico, cabe reiterar, será objeto de freqüentes discussões até os anos vinte. Nessa busca de uma peculiaridade do fílmico, os primeiros cronistas realizam um duplo movimento: separam o cinema do teatro (a premissa segundo a qual o cinema não é nem deve ser teatro filmado constitui um verdadeiro tópico), mas, simultaneamente, aproximam o cinema do romance. Esta espécie de operação "ca-

derão ser evocados como nas sessões espíritas, ser chamados da eternidade para ser obrigados a falar, a se mover, a voltar à vida; eles, que tão confortáveis devem estar no país dos espectros. Qualquer um poderá ter seus mortos queridos gravados em uma película fotográfica sistema Lumière, e lançá-los daí, por meio da lanterna mágica, à branca tela para vê-los animar-se ao mesmo tempo que o fonógrafo fala com a própria voz daqueles que existiram [...] O mundo avança, não há dúvida; estamos a caminho da imortalidade."

${ }^{5}$ Evidentemente existe um conjunto de experiências cinematográficas paralelas a esta linha hegemônica, voltada para a experimentação das dimensóes lírico-poéticas da imagem. Mas são minoritárias nos próprios centros produtores e não constituem o foco de interesse privilegiado neste ensaio. 
- (GONZÁlES CASANOVA, Manuel (org). El cine que vió Fósforo. México: Fondo de Cultura, 2003: 133.) sada" aparece com nitidez em duas das notas redigidas por Fósforo, pseudônimo dos mexicanos Alfonso Reyes e Martín Luis Guzmán. Na primeira delas, intitulada "El actor cinematográfico", de 1915, a reprise de um filme protagonizado por atores da Comédie Française suscita a seguinte consideração:

La película es de lo más escogido que conocemos: buen argumento, buenos actores (de la Comédie Française), escenarios lujosamente montados. Sin embargo, pronto se ve que la vista no es de hoy: nos parece una comedia hábilmente adaptada al cinematógrafo, pero no una creación cinematográfica... ¿Qué significaría para una de nuestras grandes cintas actuales el simple concurso de comediantes distinguidos? Estos, por buenos que sean, no pueden improvisar la nota característica de los actores formados en las necesidades del cinematógrafo. Del cine a teatro hay largo trecho. Se acerca aquél de tal modo a la verdad física de las cosas, que de su seno han brotado, de carne y hueso, los personajes imaginarios de los libros de aventuras.

Como é possível constatar, se entre o cinema e o teatro há uma distância enorme, entre o cinema e o romance de aventuras parece haver apenas um passo, familiaridade mais bem explicitada em outro artigo do mesmo ano, intitulado justamente "El cine y el folletín”. Nele, os autores afirmam:

El cinematógrafo como entretenimiento popular - es decir, como recreación que está al alcance y gusto de la mayor parte de las clases sociales - no es comparable a ningún otro de la vida moderna. [...] Si queremos hallar algo cuya función se acerque en parte a la del cine, y que, como éste, tenga la virtud de producir estados de ánimos generales, hemos de buscarlo en el campo literario y hacia las regiones más humildes: lo encontraremos en el folletín, en que había, como en el cinematógrafo - aunque en cantidad mínima si se quiere - ese elemento en que descansa toda obra de arte que remeda el vivir humano: la estética inherente a la acción... Hay, sin embargo, una diferencia esencial. En el folletín, la acción va acompañada de mala literatura; en tanto que en el cine, al desaparecer el verbo, se aleja el problema de estilo y queda sola la acción. *

Resgatando a qualidade "essencial” do cinematógrafo já destacada por Urbina, porém em um contexto decididamente narrativo, a "verdade física das coisas" (projetadas na tela) alia-se aqui a uma estética de feição folhetinesca: a "estética inerente à ação" que evoca o viver humano... enquanto ação e somente através da ação. Superior ao folhetim, visto que graças à "desaparição do verbo" "afasta-se o problema do estilo", da "má literatura" enquistada no gênero, o bom cinema é um folhetim aperfeiçoado. Elogio 
ambíguo, menos por causa do termo comparativo que se escolhe (sobre cuja origem "bastarda" é desnecessário insistir), que pelo fato de limitar, no ato do elogio, o âmbito de excelência do especificamente cinematográfico. Explico-me: se por um lado sustenta-se que o cinema realiza e figura, de maneira plena, acabada, exemplar, aquilo que o folhetim literário prefigura de modo deficiente e espúrio; por outro lado, o mérito suplementar do fílmico decorre em boa medida de uma dupla subtração: a do verbo entendido como sinônimo de "má literatura", mas também a dos processos introspectivos, dos estados “interiores", da subjetividade, que, dessa forma, permanecem potencialmente como patrimônio do verbal (da "verdadeira" literatura talvez?). Ainda em outras palavras: o mérito que cabe à parte "boa" do folhetim literário, e que o cinema eleva a um patamar "superior", vincula-se a um dizer/escrever que já no próprio seio da literatura tenderia a "apagar-se" enquanto tal, em benefício da representação ou figuração de um puro fazer, de uma estética da ação pura. O bom cinema é dinâmico por natureza, solidário da verdade física das coisas, das ações visíveis que "falam por si sós", sem necessidade de "suplementos".

Sem dúvida, o fato de estarmos em plena era do cinema mudo - embora as tentativas de torná-lo falado sejam uma constante desde o início - mas, sobretudo, de estarmos ainda em meados da década de dez, ${ }^{6}$ tem importância decisiva nesta maneira de ver as coisas; sem dúvida, não poucas das considerações mais lúcidas da época sobre a nova arte emergente são aquelas que proclamam a autonomia da imagem cinematográfica silente. Daí, inclusive, a condenação dos letreiros. Mas a justeza dessas apreciações não invalida o fato de que, ao mesmo tempo, e valendo-se das mesmas premissas, esteja dirimindo-se quem pertence à esfera do "interior" e reservando-se essa esfera à linguagem. Na negociação desse limite, desenham-se à contraluz as tensôes "internas" de uma tradição que se defronta com um concorrente poderosíssimo.

O repúdio ao uso dos letreiros constitui uma conseqüência lógica e simultaneamente um desdobramento técnico da valoração do cinético enquanto tal, legível em vários artigos da década

\footnotetext{
${ }^{6}$ Lembre-se que um filme como $O$ nascimento de uma nação, espécie de nascimento da gramática cinematográfica clássica, data de 1915, Intolerância, de 1916 e Lírios partidos, de 1919, apenas para mencionar alguns exemplos.
} 
de dez como o seguinte texto, também de autoria de Fósforo ( $E l$ Imparcial, 10/6/1916), acerca da adaptação de um dos romances de Amicis:

El cine suele aprovechar los asuntos de la literatura, y casi no hay drama cinematográfico en que no se puedan rastrear las fuentes más o menos "folletinescas" [...] Los episodios del Corazón, de Amicis, han sido filmados con muy poca fortuna. En la cinta De los Apeninos a los Alpes, por ejemplo, las fotografías se suceden como otras tantas ilustraciones al texto: los personajes apenas obran, y se contentan con aparecer y borrarse; de manera que lo principal son los letreros que nos van contando la historia. Y el letrero es el enemigo del cine.*

Ora, ainda que o desprezo pela intromissão de uma palavra que gera "contos ilustrados" e não filmes constitua um dado freqüente, trata-se de uma condenação que não implica per se a reordenação categórica das esferas de incumbência às quais me referi (externo/ interno, objetivo/subjetivo). Será preciso que se reconheça à câmera a capacidade de pensar, de sonhar, de expressar uma psicologia, para que a questão do letreiro ganhe um alcance maior. Mudança de ótica que parece exigir tanto o amadurecimento dos meios expressivos do relato cinematográfico "mudo" quanto uma sensibilidade literária mais aberta aos recursos da prosa experimental.

Duas notas cronologicamente pouco distantes, mas significativamente distintas, ilustram bem a postura tradicional que resiste, por um lado, e o novo olhar que enxerga no cinema a possibilidade de ir além, por outro. A primeira delas pertence a Urbina, maravilhado com a "maravilha técnica" mas renitente, até o fim a nota data de 1928 e o escritor está com sessenta e tantos anos de idade -, em conceder ao cinema capacidades e direitos equiparáveis aos da literatura. A segunda é de Jaime Torres Bodet, um intelectual mais jovem, que nasce e cresce ao mesmo tempo que o cinema.

Em "El cinematógrafo y la literatura", Urbina retoma com pormenores algumas das questôes apontadas até o momento, comparando as potencialidades da "descrição gráfica" (na verdade, cinemato-gráfica) e da "descrição verbal", em um contexto em que, segundo o autor, "os literatos abandonam a letra e recorrem à imagem", em que "deixam de usar os procedimentos verbais e os substituem pelos visuais”. Trata-se de uma mudança na qual Urbina vê 
uma "acomodação ao gosto e hábitos reinantes", além de "motivações econômicas", mas não necessariamente motivações artísticas. Transcrevo uma passagem do texto:

El cinematógrafo se ha impuesto a la Ciencia, al Arte, a la Historia, a la Política. Es un factor expansivo que, borrando las fronteras del idioma, es más expresivo y claro que la palabra misma.

La descripción gráfica le lleva indiscutibles ventajas a la descripción literaria. De manera que el mundo de las cosas está absolutamente subyugado. La vida exterior, con sus perspectivas, sus luces y movimientos, se manifiesta sin esfuerzo, con absoluta fidelidad. No tiene la imaginación que hacer - como frente a la página de un libro - trabajo alguno de reconstrucción. La retina se encarga, como en la existencia real, de llevar al cerebro las imágenes recogidas en el lienzo donde se proyecta la vertiginosa y maravillosa cinta fotográfica.

Mas he aquí que todo cuanto se aclara del mundo exterior, se desvanece y pierde en el mundo interior.

El cinematógrafo no tiene psicología o la tiene muy embrionaria y difusa. El cinematógrafo es mudo. La naturaleza que reproduce, habla; pero nosotros no la oímos. Somos, ante ella, un público de sordos. La vida así, carece de una suprema fórmula de expresión: el sonido. La actividad de los ojos es grande, $y$ al mismo tiempo, absoluta la inactividad de los oídos. De suerte que la imaginación, obligada a sustituir los materiales auditivos con los visuales, emprende una labor excitante. Es una tarea de atención, de penetración, mejor dicho de adivinación... Y con elementos externos trata de esbozar el universo espiritual.

Dois modos de representação diversos (imagem/palavra) são co-relacionados a outros tantos termos e funçōes (imagem/ação/ objetividade, palavra/pensamento/subjetividade), aos quais se atribui um valor diferenciado. Inicialmente, aquilo que é posto em relevo é a superioridade do visual... para a representação objetiva de espaços e de açóes. Mas trata-se de uma supremacia decorrente da "inferioridade" do código visual no que tange às operaçôes intelectuais envolvidas, do caráter imediato e concreto da imagem fílmica se comparado à abstração e complexidade do código escrito. Supremacia de "segunda classe", portanto, que logo cede seu lugar à "genuína" superioridade do verbal, à superioridade de um verbo capaz de representar os mais complexos e variados estados da alma. De fato, a subjetividade concebida no texto de Urbina não é apenas discursiva e logocêntrica: é "verborrágica", concebida como uma subjetividade que tem o poder de tudo representar e, sobretudo, de representar-se a si mesma, de explicitar-se plenamente, sem lacunas, sem interstícios "em branco". Esta capacidade conferida à
* (MIQUEL, Ángel (org). El nacimiento de una pasión... op. cit: 83-85.) 
dimensão verbal constitui para o autor um bem inquestionável se confrontada à "mudez" da imagem cinematográfica; se comparada a um "silêncio" que exige do público espectador um grande esforço de "imaginação" ou, mais ainda, de "adivinhação" a fim de atribuir sentido ao filme. Paradoxalmente, nesta segunda instância as "mesmas operaçōes" trocam seu signo de valor. Com efeito, se a "economia de esforços perceptivos" que comanda a recepção das descrições gráficas foi depreciada em nome da riqueza e complexidade dos estados de alma representados pela palavra, agora, contrariamente, é o trabalho imaginativo solicitado pelo código visual - um trabalho que deveria, a princípio, ser considerado um valor - aquilo que se apresenta como falta, como carência, como déficit. Ao longo desta argumentação certamente sinuosa opera-se sub-repticiamente, por outro lado, um deslocamento do registro escrito para o oral: o cinematógrafo é "mudo", ao passo que a natureza "fala"; não conseguindo "ouvi-la", o público espectador se torna "surdo".

Se destaco esse conjunto de expressóes é porque, em parte, elas acenam em direção ao que está prestes a nascer, o cinema falado, o qual reordenará mais uma vez, e não sem dificuldades, idas e voltas, avanços e recuos, os termos do debate (entre outras coisas, o cinema levará um bom tempo depois de começar a falar para apreender a "calar", para que o dito não seja mera reverberação do que a imagem mostra e/ou sugere). Mas, além disso, porque aquilo que se define aqui como "defeito" ou menos-valia da imagem visual (o fato de que o espectador deva "adivinhar" o não dito por causa da ausência de palavras, o fato de que seja obrigado a "propor" sentidos para o que não se nomeia) é precisamente o que será considerado uma "lição" (do cinema) a ser emulada: sugerir, "sem dizer", através do que é mostrado ou insinuado; deixar "lacunas", "brancos" a serem preenchidos pela colaboração do receptor.

Na concepção limitada e limitante de Urbina, "apesar de seus triunfos, o cinematógrafo jamais nutrirá a cultura", "nem aperfeiçoará o espírito como o faz o livro". Isso, embora a crônica se encerre com o cronista... indo ao cinema.

A longa nota de Jaime Torres Bodet sobre A última gargalhada, filme de Murnau caracterizado pela "ausência absoluta de títulos" (letreiros), propõe uma visão radicalmente diferente, dado que 
para Bodet a câmera "pensa, sonha, expressa uma psicologia", e o faz de maneira exemplar. Cito vários trechos do artigo que considero reveladores desta mudança de ótica:

Hace algunos días una película de Emil Janning se anunció al público con el aliciente de esta novedad que era el desideratum: la ausencia absoluta de títulos.

El interés que ha tenido el cinematógrafo por lograr este triunfo no se ha inspirado en un pueril deseo de habilidad técnica, aunque, analizando bien los problemas de estética universal, poco hay en la conquista de arte que no haya sido, en un principio, un pequeño y difícil juego de técnica.

Algo más substancial se agitaba, no obstante, bajo este propósito de silencio y era el descubrir la esencia y la libertad de un arte que ha vivido hasta ahora del misterio combinado de la luz y de la sombra, de la mezcla de la literatura - anguloso esqueleto cerebral - y de la pintura - música silenciosa de las formas puras.

En tanto el cine haya menester de la literatura - ¿buena? ¿mala? ¿simplemente mediocre? - de los letreros, no será sino un apéndice ilustrado, ciertamente muy rico pero sólo un apéndice de la novela. Hasta ahora el cinematógrafo se había resignado a esta situación y aún había encontrado el modo de hacerla más decorosa, perfeccionando, junto con su estilo, la gracia pintoresca de su psicología y la decorativa riqueza de su paisaje exterior.

Pero lo estable está reñido con la vida [...] Las artes tienen su Bastilla y Janning acaba de apoderarse de ella [...].

Un invento: la cámara que piensa

Al desaparecer el andamiaje de los letreros que el cinematógrafo norteamericano llegó a organizar [...] ha nacido un nuevo compromiso para la cámara fotográfica.

Hasta ahora la cámara animó los personajes inmóviles del letrero. Pero esto [...] ha dejado de ser interesante. Lo que urge es unir más directamente los resultados de la fotografía y nuestro espíritu: faible et pensant de que hablaba Pascal.

Suprimidos los nombres y los antecedentes particulares de los personajes, desaparece el interés del diálogo, que simulaba el temblor sintético de la tragedia, sin que las figuras de la pantalla pierdan un ápice de su interés vital.

Ya no somos simples espectadores de un drama, sino los miembros de una acción que estamos viviendo directamente.

De qué servía, en verdad, todo ese fardo de las películas ¿"habladas”? ¡Nombres! ¡Historia! ... Lejanía pura, reflejo de esa obsesión de desarrollo sucesivo.

Alegrémonos de que el cinematógrafo haya aceptado, por una vez, las dificultades en que habrá de descubrir este doble tesoro: sus límites y su profundidad.

[...]

De la importancia de soñar 
" "La última risa. Una paradoja: el cinematógrafo mudo" (1926). In: TORRES BODET, Jaime. La cinta de Plata. $\mathrm{SCH}$ NEIDER, Luis (org). México, Unam, 1986: 175-177.)

- (El Universal, 12/12/1920.)

- (MIQUEL, Ángel (org). Los exaltados..., op. cit.: $177-$ 178.)
Las escenas más perfectas de La última risa son precisamente aquellas en que el personaje central [...] sueña reconquistar la fuerza perdida y, con ella, la honorable situación que ocupara durante años en el hotel. Hay allí una fusión de lo subconsciente vivo y del plano oblicuo del sueño que es un admirable triunfo de exactitud y de psicología.As cenas mais perfeitas de $A$ última gargalhada são precisamente aquelas em que a personagem central [...] sonha reconquistar a força perdida e, com ela, a honrosa situação que ocupara durante anos no hotel. Há aí uma fusão do subconsciente vivo e do plano oblíquo do sonho que é um admirável triunfo de exatidão e de psicologia.

Não muito distinto foi o argumento de Carlos Noriega Hope, vários anos antes, ao comentar uma das tantas tentativas de sonorização do cinema em seu artigo El cinematógrafo hablado:

Nuevamente han gritado los periódicos la gran noticia en Berlín: ya existen salones cinematográficos donde se representan comedias y revistas habladas. [...]

Sinceramente creo que todas las artes deben ser independientes y alejarse de toda parodia artística. ¿No es acaso ridículo imitar a un teatro con voces y sombras, acabando con un arte original y distinto? El cinematógrafo, para mí, es superior muchas veces al drama y a la comedia, precisamente porque deja al espectador, un margen de fantasía. Todos nosotros sabemos que las cosas completas son siempre demasiado defectuosas y por eso admiramos más el rudo Pensador de Rodin que cualquier relamida escultura de algún copista del cuerpo humano, por eso sentimos más a los autores que nos cuentan sus obras a medias, para que nosotros las completemos en nuestra imaginación, que aquellos puristas que, a fuerza de ser impecables acaban por ahogar la emoción de la literatura.

El cinematógrafo era, pues, un divino arte imperfecto. Nosotros - por un raro fenómeno de sustitución - podíamos pensar como los personajes [...] Hoy desgraciadamente la ciencia terminará con todo esto [...]. La ciencia matará al cinematógrafo [...] y nosotros huiremos entonces de los grandes teatros donde se haga "cine hablado" para refugiar nuestra melancolía en algún primitivo cine de arrabal, hasta donde, dichosamente, no llegue aún la calva augusta de la Ciencia.*

O caminho percorrido pelos escritores-cronistas em pouco mais de vinte anos parece ter dado uma "volta completa" e reencontrado, no "fim" do trajeto, os mesmos tópicos das notas redigidas por Nervo, Tablada ou Urbina, quando das primeiras projeções cinematográficas, porém, carregados de uma valência oposta à inicial, virados pelo avesso, invertidos: a "maravilha técnica" que permitia augurar o aperfeiçoamento da cópia e a reprodução consumada da "verdade física das coisas" agora ameaça "matar" o cine- 
ma no que ele tem de "imaginativo" e de "artístico", obrigando-o a "falar"; o que se conta ou mostra de modo "inacabado" ao dar margem à "fantasia" torna-se um estímulo para a imaginação e colaboração ativa do espectador, dá forma a uma "divina arte imperfeita" (e o divino dessa arte reside precisamente na incompletude); a "obsessão pelo desenvolvimento sucessivo", típica de uma consciência concebida em termos tradicionais, apresenta-se agora como algo perimido, obsoleto, e cede seu lugar à "fusão do subconsciente vivo" e ao "plano oblíquo do sonho", meio idôneo para alcançar através de puras imagens um "triunfo de exatidão e de psicologia" (de uma psicologia concebida em outros termos, é claro); a emancipação em relação ao "literário" (em sua dupla manifestação de letra/letreiro e de romance/relato linear) torna-se uma conquista da estética da lente; a maioridade e a "independência das artes" (que se proclama, entretanto, lançando mão de co-relações inter-artísticas ou inter-culturais: Rodin, a escultura, a fotografia, as meditações de Pascal, a noção de subconsciente, etc.) parecem bater finalmente às portas do cinema - e inclusive o cinema talvez tenha algo a "dizer" ou "ensinar" à própria literatura, constatação que obrigaria a percorrer uma segunda vez o "mesmo" trajeto aqui traçado, mas desta vez na contramão, no sentido das influências exercidas pelo cinematográfico na letra (a rigor, ao invés de postular uma "mudança” na direção das influências seria mais adequado referir-se a este processo em termos de co-incidências, de con-fluências, de fluxo de ida e volta). Nesse outro trabalho (cabe lembrar que o presente artigo é uma pequena amostra de uma investigação maior), os mesmos escritores que se recusam a aceitar o valor artístico do cinema poderiam, por vezes, servir como exemplo, tal como o prova uma crônica do próprio Urbina intitulada "Cinematógrafo da vida", datada de 1907, e aparentada em vários aspectos à magnífica apresentação redigida por João do Rio para seu livro de crônicas urbanas lançado no mesmo ano: Cinematógrafo das Letras. Aí, é a percepção, a consciência, a psicologia e o estado de alma do sujeito que "fala" que se tornam uma espécie de "cinematógrafo", abrindo a possibilidade de novas formas de escrita a serem projetadas no papel em branco. Trata-se de um "filme" que começa a ser rodado muito cedo, sem dúvida alguma, e que levarão a cabo em boa medida, não apenas no México como em outros países da América Latina, os escritores sensibilizados com as propostas da vanguarda - ainda que não só eles, nem necessariamente eles. No caso do México, especifica- 
mente, Gilberto Owen, Xavier Villaurrutia, González Rojo e o já citado Jaime Torres Bodet são, entre outros, os que realizam a tarefa. Mas isso já é matéria para outro ensaio.

\section{Miriam V. Gárate}

Miriam V. Gárate é professora da Unicamp (Departamento de Teoria Literária). Realizou Estágio Pós-Doutoral (Bolsa Capes) em El Colegio de México e o Instituto de Investigaciones Estéticas-Unam no segundo semestre de 2007. O presente artigo é resultado parcial dessa pesquisa maior. Publicações recentes: "Crítica cinematográfica y ficción en Horacio Quiroga”. Revista Iberoamericana, vol LXXIV. Pittsburgh: University of Pittsburgh, $\mathrm{n}^{\circ} 222,2008$; "Estética y crítica cinematográfica en las páginas de Martín Fierro". In: CROVETTO, P.L; SANFELICI, L. (org.). Palabras e ideas. Ida y vuelta. Roma: Editori Riunti, 2008; "Notas de trabalho sobre Horacio Quiroga. Literatura, cinema, psicanálise: projeçôes e interseçōes de campo". Revista Literatura e Sociedade, no 10. São Paulo: USP; no prelo).

Palavras-chave: tradição letrada; cinema mudo; crônicas cinematográficas mexicanas.

\section{Resumo}

Durante o período em que o cinema surge e se desenvolve como espetáculo mudo, a reflexão acerca de suas as relações com a escrita e, em um sentido mais amplo, com a linguagem verbal, organiza-se basicamente em torno a três eixos: graus de afinidade ou discrepância existentes entre os gêneros literários utilizados como fonte e os atributos da imagem cinematográfica; função dos letreiros nesse contexto; potencialidades e limitaçōes "inerentes" às linguagens cinético-visual e verbal. $\mathrm{O}$ tratamento dado a essas questóes em algumas crônicas mexicanas das primeiras décadas do século XX revela as tensóes internas, resistências e mudanças de ótica dos setores letrados perante a nova arte. 
Abstract

During the period in which the cinema emerges and develops as a silent spectacle, the reflection about its relation with the written language and, in a broader sense, with verbal language, is basically organized around three axes: degrees of affinity or discrepancy among the literary genres used as sources and the attributes of cinematographic language; the function of subtitles in this context; the potentialities and limitation "inherent" to the visual-kinetic and verbal languages. The way these issues were dealt with in the Mexican chronicles in the first decades of the $20^{\text {th }}$ century reveals the internal tensions, the resistances and changes of view in the literate sectors of society facing this new art.

\section{Resumen}

Durante el período en que el cine surge y se desarrolla como espectáculo mudo, la reflexión acerca de sus relaciones con la escritura y, en un sentido amplio, con el lenguaje verbal, se organiza básicamente en torno a tres ejes: grados de afinidad o discrepancia existentes entre los géneros literarios utilizados como fuente y los atributos de la imagen cinematográfica; función de los letreros en ese contexto; potencialidades y limitaciones "inherentes" a los lenguajes cinetico-visual y verbal. El tratamiento dado a estas cuestiones en algunas crónicas mexicanas de las primeras décadas del siglo XX revela las tensiones internas, resistencias y cambios de óptica de los sectores letrados frente al nuevo arte.
Key words: literate tradition silent movies; Mexican cinematographic chronicles.

Palabras Ilave: tradición letrada; cine mudo; crónicas cinematográficas mexicanas. 